\title{
Modeling and Simulation for a Tractor Equipped with Hydro-Mechanical Transmission
}

\author{
Seok Hwan Choi ${ }^{1}$, Hyoung Jin Kim ${ }^{1}$, Sung Hyun Ahn', Sung Hwa Hong', Min Jae Chai ${ }^{1}$, Oh Eun Kwon ${ }^{1}$, \\ Soo Chul Kim², Yong Joo Kim², Chang Hyun $\mathrm{Choi}^{3}$, Hyun Soo Kim* \\ ${ }^{1}$ School of Mechanical Engineering, Sungkyunkwan University, Suwon, Korea \\ ${ }^{2}$ LS Mtron LTD., Anyang, Korea, ${ }^{3}$ Department of Bio-Mechatronic Engineering, Sungkyunkwan University, Suwon, Korea
}

Received: May 21 $21^{\text {th }}, 2013$; Revised: June $30^{\text {th }}, 2013$; Accepted: August $7^{\text {th }}, 2013$

\section{Abstract}

Purpose: A simulator for the design and performance evaluation of a tractor with a hydro-mechanical transmission (HMT) was developed. Methods: The HMT consists of a hydro-static unit (HSU), a swash plate control system, and a planetary gear. It was modeled considering the input/output relationship of the torque and speed, and efficiency of HSU. Furthermore, a dynamic model of a tractor was developed considering the traction force, running resistance, and PTO (power take off) output power, and a tractor performance simulator was developed in the co-simulation environment of AMESim and MATLAB/Simulink. Results: The behaviors of the design parameters of the HMT tractor in the working and driving modes were investigated as follows; For the stepwise change of the drawbar load in the working mode, the tractor and engine speeds were maintained at the desired values by the engine torque and HSU stroke control. In the driving mode, the tractor followed the desired speed through the control of the engine torque and HSU stroke. In this case, the engine operated near the OOL (optimal operating line) for the minimum fuel consumption within the shift range of HMT. Conclusions: A simulator for the HMT tractor was developed. The simulations were conducted under two operation conditions. It was found that the tractor speed and the engine speed are maintained at the desired values through the control of the engine torque and the HSU stroke.

Keywords: CVT (continuously variable transmission), HMT (hydro-mechanical transmission), Simulation, Tractor performance

\section{Introduction}

As the concerns on environmental issues such as global warming and the climate change have been growing, regulations on emission such as EURO-6, TIER-4, and the Enforcement Rule of the Clean Air Conservation Act, are being tighten. In response to these concerns, active research on and development of eco-friendly technologies have been increasing in tractor design.

The existing transmissions for tractors include manual transmission, power shift transmission, HST (hydro-static transmission), and HMT (hydro-mechanical transmission).

\footnotetext{
*Comesponding author: Hyun Soo Kim

Tel: +82-31-290-7438; Fax: +82-31-290-7679

E-mail: hskim@me.skku.ac.kr
}

Among these, HST and HMT have the CVT (continuously variable transmission) feature and can operate the engine with high thermal efficiency independent from the vehicle speed within the transmission range, thus reducing the fuel consumption and exhaust. In addition, because they can automatically control the gear ratio with no separate gear lever operation of the driver, and because they can increase the working efficiency by reducing the driver's labor, they are expected as promising transmissions that are eco-friendly and highly efficient.

HST transmits power using hydraulic pressure, and has the advantages of having a continuously variable transmission function and of being capable of transmitting very large power per unit weight. It has been usually applied to small tractors, however, due to its considerably 
lower efficiency compared to the mechanical transmission. To make up for this shortcoming of HST, active studies on HMT that combines a compound planetary gear with HST to improve the system efficiency and to extend the transmission range are being conducted. As HMT is composed of an HSU (hydro-static unit) and a compound planetary gear unit, it has a hydraulic path that transmits power from the engine through the HSU, and a mechanical path that transmits power through the compound planetary gear. The higher percentage of power transmitted through the mechanical path is, the higher the system efficiency becomes.

As the gear shift of HMT is performed by considering the HSU and the load characteristics, a study on the HSU, which is used as a continuously variable transmission variator in HMT, should first be required. The past studies on the modeling and hydraulic characteristics analysis of HSU include a study by Steyr on the mathematical modeling of the pump, motor, and swash plate of HSU used in the S-matic transmission (Aizetmüller, 2000; Kugi et al., 2000), a study on the calculation method of loss and efficiency through the numerical calculation of HSU (Ortwig, 2002), and a study on the power transmission efficiency of off-road vehicles through the steady-state mathematical model of diesel/CVT power split transmission (Casoli et al., 2007; Xu et al., 2010). In addition, the response and leakage characteristics of a variable pump system were investigated through an experiment (Park et al., 2002), and the traction performance of a tractor was estimated based on the interaction between the tire and the soil (Lee et al., 2009). Compared with studies on working implements and power shift clutches, few studies on dynamic-behavior analysis using the modeling and simulation of HSU and HMT have been performed.

In this study, a simulator that can be used for the design and performance analysis of HMT tractors was developed based on the dynamic model of the HMT by considering the HSU, swash plate control system, planetary gear, tractor longitudinal dynamics and load characteristics. Using the simulator, performance of the HMT tractor was investigated.

\section{Materials and Methods}

\section{HMT modeling}

Figure 1 shows a schematic diagram of the HMT under study.

HMT consists of an HSU and a planetary gear. The planetary gear is composed of single pinion planetary gears (SPPG) and has an output split structure, where the planetary gear is located at the output side. In this study, it was assumed that the planetary gear has a single-speed with gear ratio of 1:2.

\section{$H S U$}

HSU consists of a hydraulic pump and a hydraulic motor. As the pump cylinder block rotates, the oil flow is forced out of the pump at high pressure. As the high pressure oil flow enters the hydraulic motor, the pistons of the motor are pushed against the fixed swash plate and slide down the declined surface. Then the output shaft rotates with the motor cylinder block. This drives the machine and the angle of pump swash plate determines the output shaft speed. The speed of the hydraulic motor is controlled by the angle of the swash plate continuously.

Table 1 shows the specifications of the HSU under study(Bosch Rexroth, A4VG series). The variable-displacement axial piston type hydraulic pump discharges $45 \mathrm{cc} / \mathrm{rev}$ at the maximum swash plate angle, and the swash plate is controlled by two solenoid valves. The fixed-displacement axial piston type hydraulic motor constantly discharges $45 \mathrm{cc} / \mathrm{rev}$. The pump and the motor are connected through the inlet and outlet, respectively. Between the two units, there are a pressure relief valve and a flushing valve to prevent excessive pressure rise, and a charging pump and a check valve to charge the leakage oil and to maintain the minimum line pressure.

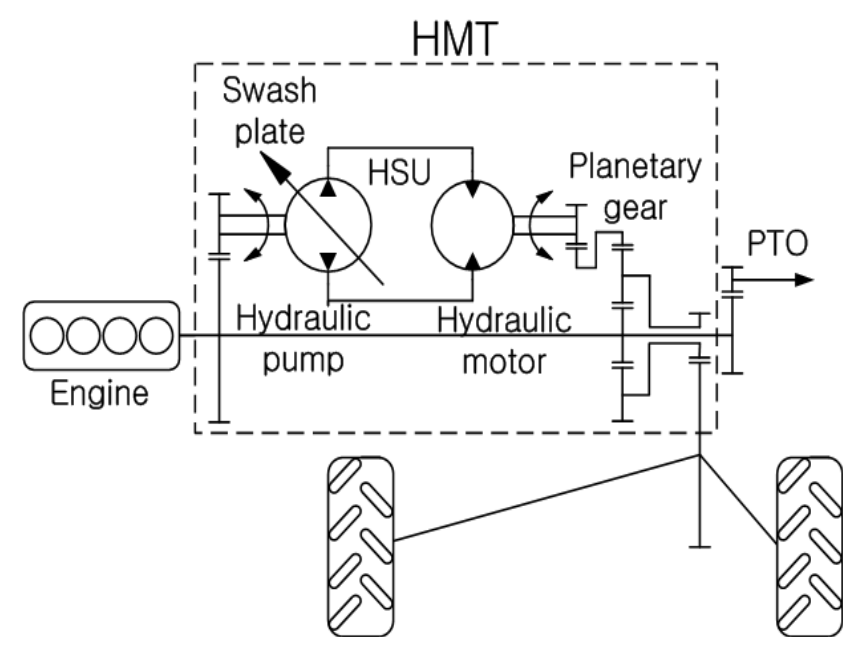

Figure 1. Schematic diagram of the HMT. 


\begin{tabular}{ccc} 
Hydraulic pump & Type & Variable-displacement axial piston \\
Hydraulic motor & Displacement (cc/rev) & Fixed-displacement axial piston \\
& Type & 45 \\
Max. operating pressure (bar) & Displacement (cc/rev) & 450 \\
Swash plate control pressure $(\mathrm{bar})$ & 18 \\
Swash plate operating angle $\left({ }^{\circ}\right)$ & $-15 \sim 15$ \\
\hline
\end{tabular}

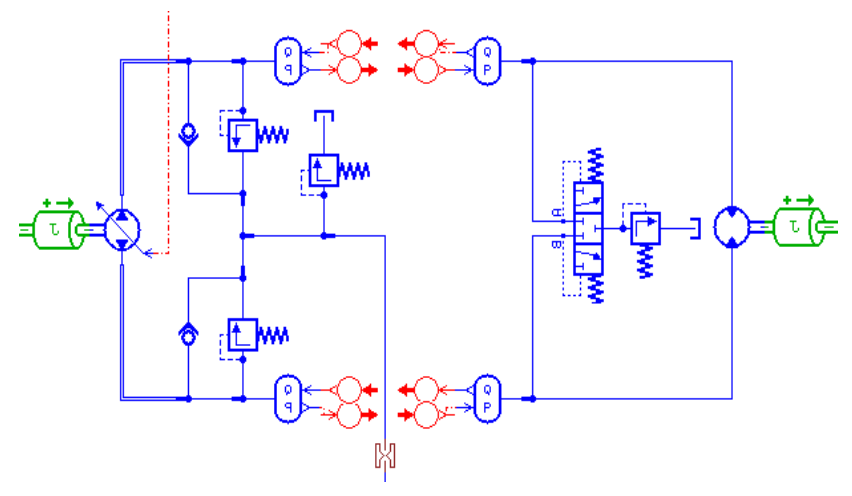

Figure 2. AMESim model of the HSU.

The relationship between the input/output speed and the torque of HSU are as follows:

$$
\begin{aligned}
& T_{H S U-\text { out }}=T_{H S U-i n} \times \frac{\eta_{\text {mech }}}{i_{\text {stroke }}} \\
& \omega_{H S U-\text { out }}=\omega_{H S U-i n} \times i_{\text {stroke }} \times \eta_{\text {vol }}
\end{aligned}
$$

where $T$ and $\omega$ are the torque and speed, $i_{\text {stroke }}$ is the HSU pump stroke (-1 1), $\eta_{v o l}$ is the volumetric efficiency of the HSU, and $\eta_{\text {mech }}$ is the mechanical efficiency of the HSU. The subscripts out and in mean the output and input, respectively.

In the above expressions, the input and output are determined by the direction of the power flow towards the HSU. For example, if the power flows from the pump to the motor, the speed and torque of the pump are the input, and the speed and torque of the motor become the output. HSU was modeled using the software AMESim (Figure 2)(LMS Imagine, 2010). For the volumetric and mechanical efficiency of HSU, the HSU characteristic test results supplied by the manufacturer were used in Figure 3 and Figure 4.

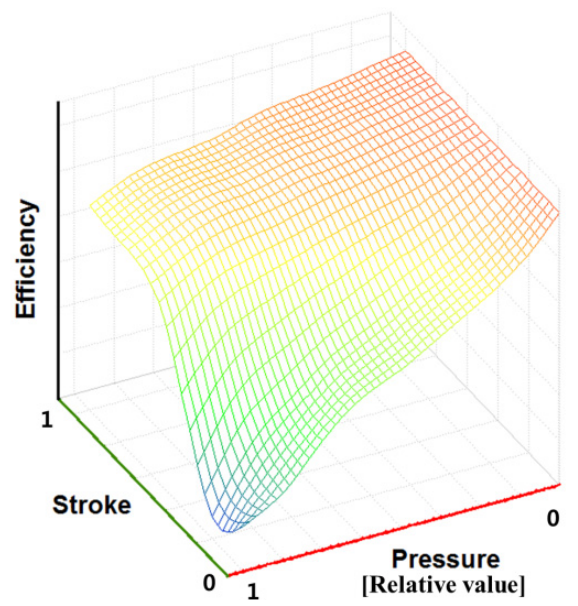

Figure 3. HSU volumetric efficiency at pump speed $3200 \mathrm{rpm}$.

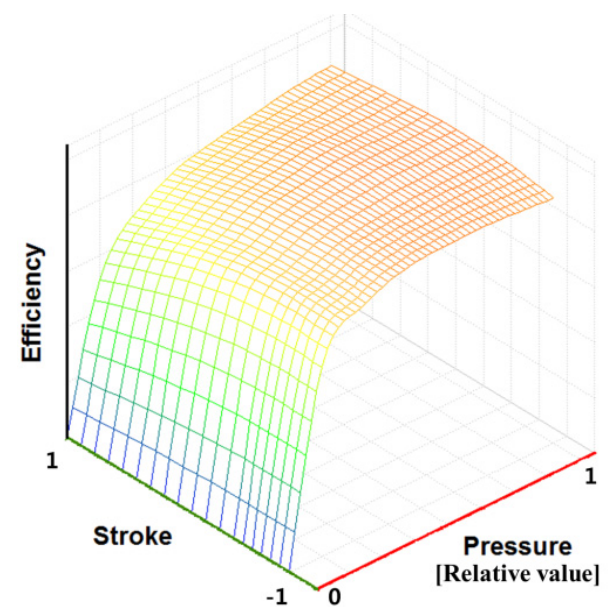

Figure 4. HSU mechanical efficiency at pump speed $3200 \mathrm{rpm}$.

\section{Swash plate control system}

Figure 5 shows the structure of the swash plate control system. The swash plate control system is a mechanical type servo valve consisting of a directional spool valve to which two solenoid valves are connected, a double-acting cylinder for moving the swash plate, and a link for connecting these two components. In this study, dynamic 


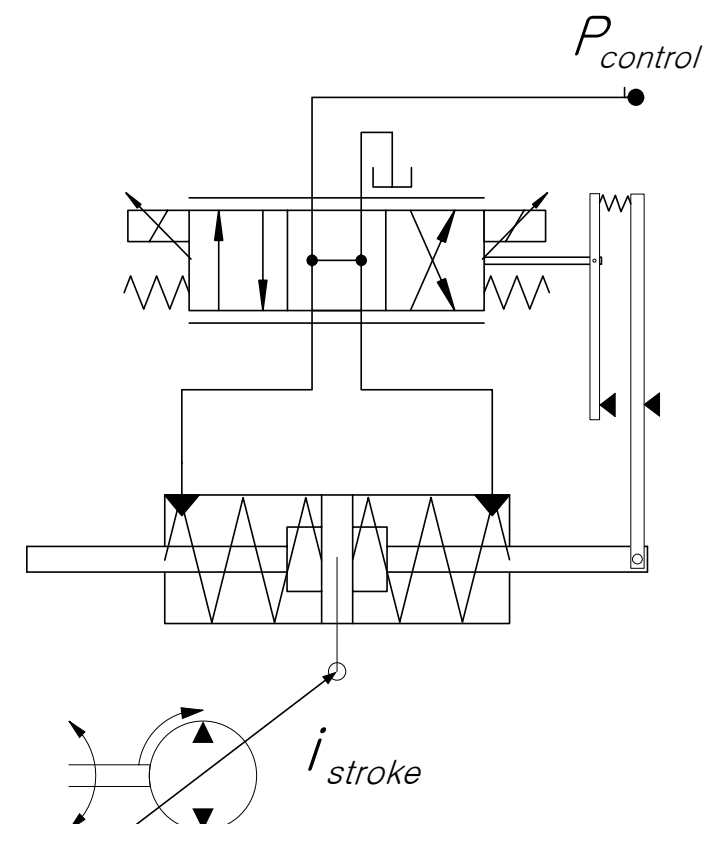

Figure 5. Swash plate control system.

model of the swash plate control system was obtained as the following 1st-order system;

$$
\frac{i_{\text {stroke }}}{P_{\text {control }}}=\frac{K}{1+\tau s}
$$

where $P_{\text {control }}$ is the control pressure of the swash plate control system, $K$ is the steady state gain, $\tau$ is the time constant, $\mathrm{s}$ is Laplace transform variable.

\section{Planetary gear}

In the planetary gear of the HMT under study, the engine is connected to the sun gear, the hydraulic motor to the ring gear, and the carrier gear to the output shaft. Figure 6 and 7 show the speed and torque levers, respectively, of the planetary gear that was used in this study. The output speed is determined by the speed ratio of the sun and ring gears from the lever, and the output torque can be determined from the moment equilibrium of the lever as,

$$
\begin{aligned}
\omega_{T M-\text { out }} & =\left(\frac{Z_{R}}{Z_{R}+Z_{S}} i_{\text {stroke }}+\frac{Z_{S}}{Z_{R}+Z_{S}}\right) \omega_{\text {engine }} \\
T_{T M-\text { out }} & =\frac{Z_{R}+Z_{S}}{i_{\text {stroke }} \cdot Z_{R}+Z_{S}}\left(T_{\text {engine }}-J_{\text {engine }} \dot{\omega}_{\text {engine }}-T_{P T O}\right)
\end{aligned}
$$

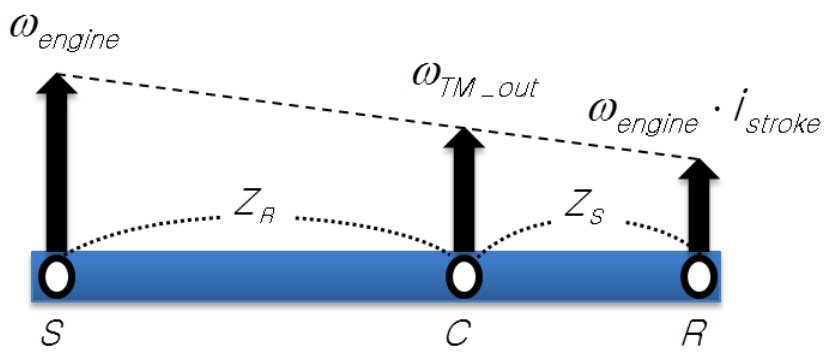

Figure 6. Speed lever.

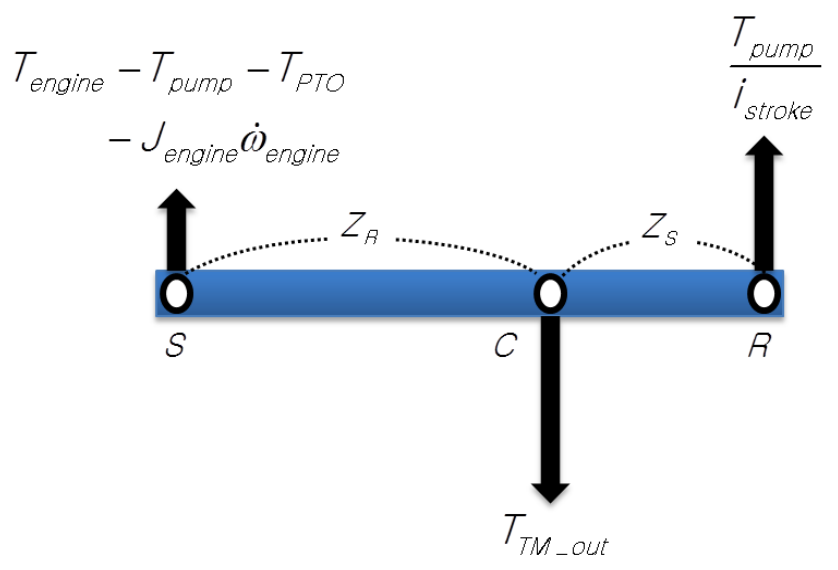

Figure 7. Torque lever.

where $Z$ is the teeth number, the subscripts $C, S$, and $R$ mean the carrier gear, sun gear, and ring gear, respectively, $\omega_{\text {engine }}$ is the engine speed, $\omega_{\text {TM-out }}$ is the transmission output speed, $T_{\text {pump }}$ is the hydraulic pump torque, $T_{P T O}$ is the PTO (power take-off) torque, Jengine is the engine inertia.

It is seen from equations (4) and (5) that the output speed and torque of HMT are expressed by the engine speed, engine torque, and HSU stroke.

\section{Tractor model}

Figure 8 shows a schematic diagram of the tractor under study.

To develop a performance simulator of the HMT tractor, a longitudinal dynamic model was developed. The specifications of the tractor are shown in Table 2.

\section{Engine}

The $70.9 \mathrm{~kW}$ engine with the torque of a $357 \mathrm{Nm}$ at the rated rpm of 2100 is used. The engine torque is determined by the engine speed and the throttle opening. Figure 9 shows an engine characteristic map indicating the torque value and the brake-specific fuel consumption 


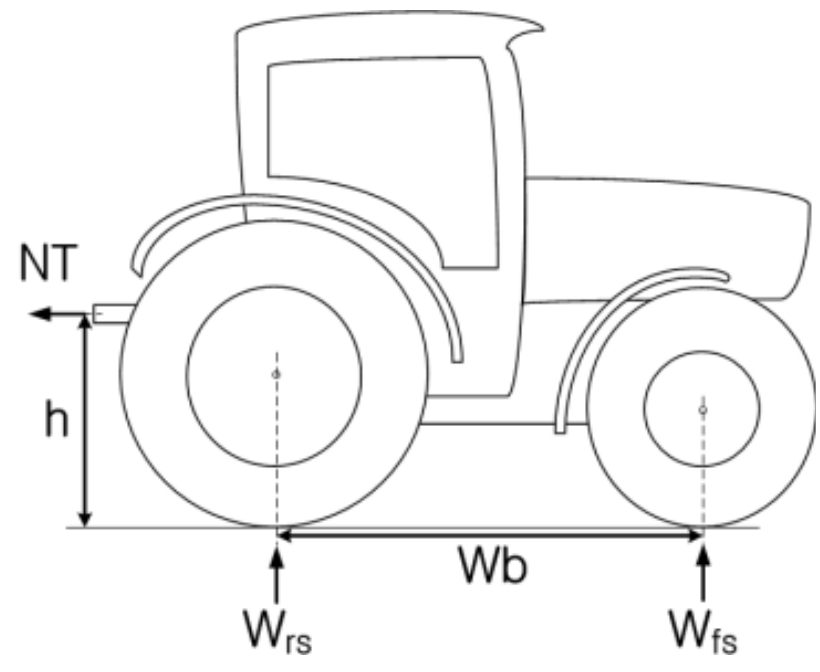

Figure 8. Schematic diagram of the tractor under study.

\section{Table 2. General specifications of the tractor}

\begin{tabular}{|cc|}
\hline Tractor parameter & Value \\
Engine power & $70.9 \mathrm{~kW}$ \\
\hline$W_{f s}$ (static front weight) & $17.4 \mathrm{kN}$ \\
\hline$W_{r s}$ (static rear weight) & $14.6 \mathrm{kN}$ \\
\hline$r_{f}$ (front tire radius) & $0.539 \mathrm{~m}$ \\
\hline$r_{r}$ (rear tire radius) & $0.738 \mathrm{~m}$ \\
Wb (wheel base) & $3.47 \mathrm{~m}$ \\
$\mathrm{~h}$ (height) & $0.51 \mathrm{~m}$ \\
\hline
\end{tabular}

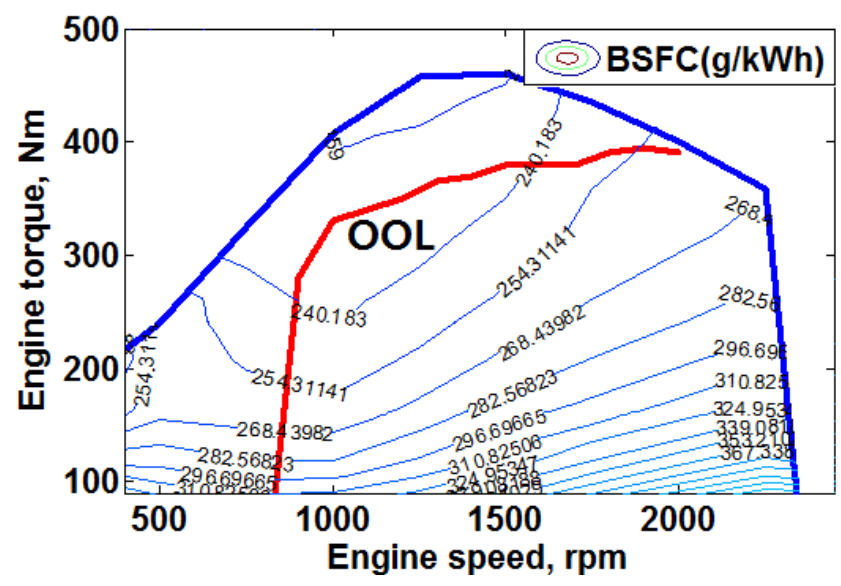

Figure 9. Engine characteristic map.

(BSFC, g/kWh). The optimal operating line (OOL) is represented by connecting the points with the best engine efficiency at each power curve. The fuel consumption can be minimized by running the engine at OOL for the demanded tractor power.

\section{Loads acting on the tractor}

The loads acting on the tractor can be divided into the drawbar load, PTO load, and load by the soil characteristics. The drawbar load is the drag force of the working implement, which determines the driving torque of the wheels and the weight distribution of the front and rear wheels of the tractor. The PTO acts as a load when the driving power of the working implement is directly connected to the engine. The load by the soil characteristics affects the tractor performance because the interaction at the ground contact surface varies by soil type. A complicated analysis is needed for this load because it changes according to the characteristics of the soil and tire. Many researchers have analyzed these characteristics through empirical methods. In this study, the model suggested by Brixius was used (Brixius, 1987; Grisso et al., 2003; 2007).

$$
\begin{aligned}
& \frac{G T}{W_{r d}}=0.88\left(1-e^{-0.1 B n}\right)\left(1-e^{-7.5 S}\right)+0.04 \\
& \frac{M R}{W_{r d}}=\frac{1}{B_{n}}+0.04+\frac{0.5 S}{\sqrt{B_{n}}} \\
& \frac{N T}{W_{r d}}=\frac{G T}{W_{r d}}-\frac{M R}{W_{r d}}= \\
& 0.88\left(1-e^{-0.1 B n}\right)\left(1-e^{-7.5 S}\right)-\frac{1}{B_{n}}-0.04-\frac{0.5 S}{\sqrt{B_{n}}} \\
& B_{n}=\frac{C l b d}{W_{r d}}\left(\frac{1+5 \frac{\delta}{h}}{1+3 \frac{b}{d}}\right) \\
& W_{r d}=W_{r s}+N T \cdot \frac{h}{W b}
\end{aligned}
$$

where $W_{r d}$ is the rear dynamic weight, $W_{r s}$ is the rear static weight, $G T$ is the gross traction force, $M R$ is the motion resistance force, $N T$ is the net traction force, $S$ is the slip ratio (0 1), $B_{n}$ is the tire mobility number, $C I$ is the cone index number of the soil, $\delta$ is the tire deflection, $h$ is the tire section height, $b$ is the tire section width, and $d$ is the overall tire diameter.

\section{Tractor dynamics}

The longitudinal dynamic equations of the tractor can be derived as follows(Ryu, K. H., 2004): 


$$
\begin{aligned}
& M \dot{V}=G T-F_{L}-M R \\
& J_{\text {engine }} \dot{\omega}_{\text {engine }}=T_{\text {engine }}-\frac{r_{r}\left(i_{\text {stroke }} \cdot Z_{R}+Z_{S}\right)}{i_{\text {frd }}\left(Z_{R}+Z_{S}\right)} G T-T_{P T O} \\
& S=-\frac{1}{7.5} I N \\
& M R=\left(\frac{1}{B_{n}}+0.04+\frac{0.5 S}{\sqrt{B_{n}}}\right) W_{r d}
\end{aligned}
$$

where $M$ is the tractor mass, $F_{L}$ is the drawbar load, $r_{r}$ is the rear tire radius, and $i_{\text {frd }}$ is the final reduction gear ratio.

As shown in equations (11) and (12), to control the tractor speed $(\mathrm{V})$ and the engine speed ( $\left.\omega_{\text {engine }}\right)$ for the given loads $F_{L}$ and $T_{P T O}$, the engine torque ( $\left.T_{\text {engine }}\right)$ and the HSU stroke ( $\left.i_{\text {stroke }}\right)$ need to be controlled.

Figure 10 shows the performance simulator of the HMT tractor using the co-simulation of AMESim and MATLAB/Simulink. The powertrain of HMT was modeled using AMESim, and the MATLAB/Simulink was used to construct the driver model, the engine throttle and HSU stroke controller, and the road load model.

\section{Simulation conditions}

To improve the working efficiency and to shorten the operating time when using PTO power such as a rotary tillage or a plowing, the engine speed and tractor speed need to be maintained at the desired values by control of the engine throttle and HSU stroke even with frequent load variations. Furthermore, for the traction or driving when the PTO power is not used, the engine needs to be operated on the 00L regardless of the tractor speed to minimize the fuel consumption. In this study, therefore, the behaviors of design parameters of the HMT tractor were examined via simulations for the following two operation conditions:

Working mode: Maintain the engine speed and tractor speed at desired values for stepwise variations of the drawbar load $\left(F_{L}\right)$.

Driving mode: Operate the engine on OOL for minimum fuel consumption when increasing the tractor speed for a constant drawbar load.

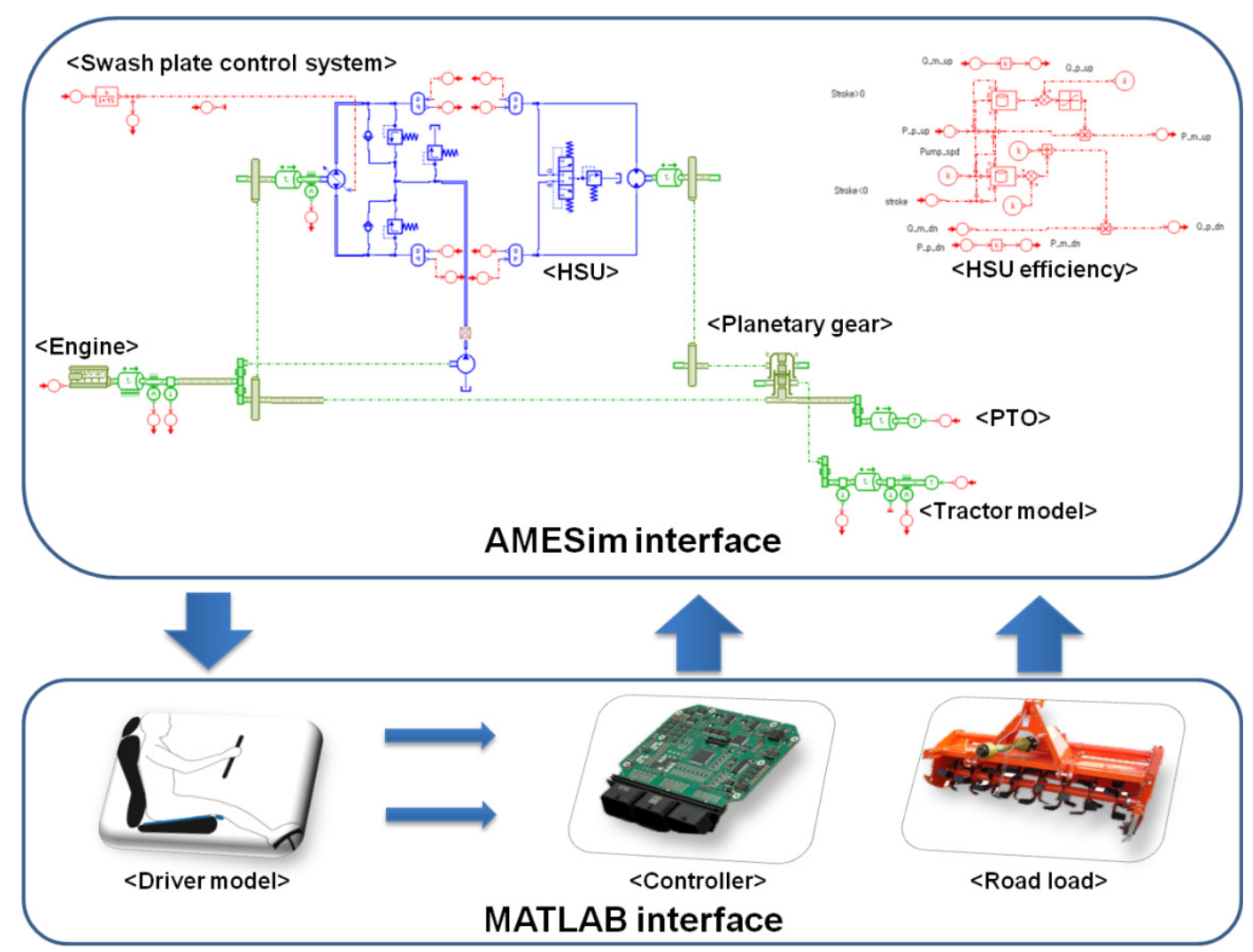

Figure 10. Tractor performance co-simulator. 


\section{Results and Discussion}

\section{Working mode}

Figure 11 shows the simulation results for the working mode (e.g. rotary tillage). For the drawbar load, as shown in Figure 11a, it was assumed that the load increased and decreased in stepwise manner during the work. At this moment, the control targets were selected as (1) the
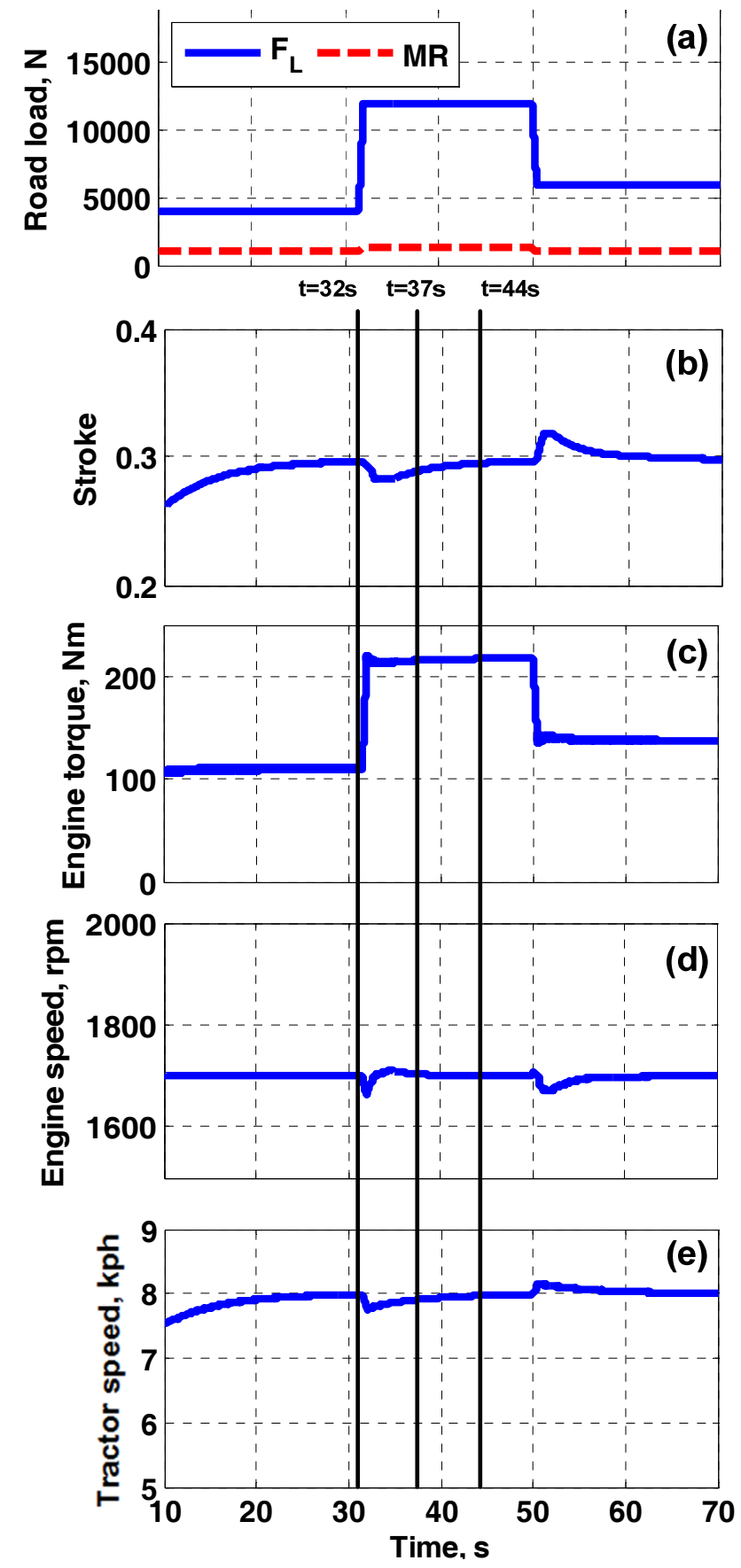

Figure 11. Simulation results for the working mode. desired engine speed of $1700 \mathrm{rpm}$ to maintain the PTO speed of $600 \sim 700 \mathrm{rpm}$ and (2) the tractor speed of 8 $\mathrm{km} / \mathrm{h}$. The simulation results show that the tractor speed and engine speed decreased due to the effect of the stepwise increase of the drawbar load at $\mathrm{t}=32 \mathrm{~s}$, but the engine speed was maintained at the desired speed at $\mathrm{t}=37 \mathrm{~s}$ by the engine torque and HSU stroke control (Figure 11b, c). The tractor speed followed the desire value at $\mathrm{t}=44 \mathrm{~s}$ after $12 \mathrm{~s}$ due to the tractor inertia (Figure 11e). When the drawbar load decreased in stepwise manner at $t=50 \mathrm{~s}$, the engine speed and vehicle speed were maintained at the target values through the decrease of the engine torque and the change in the HSU stroke.

\section{Driving mode}

Figure 12 shows the simulation results for the driving mode. For a constant drawbar load (4000 N) (Figure 12a), the desired speed of the tractor was set to increase from 0 to $12 \mathrm{~km} / \mathrm{h}$ for $50 \mathrm{~s}$ (Figure 12e). The tractor speed followed the target speed well (Figure 12e). In region A, the tractor speed showed an overshoot above the desired speed, and then followed the desired speed. This is because a large engine torque was supplied momentarily to overcome the load at a steady state when the tractor began to move. Thus, the tractor speed increased to 2 $\mathrm{km} / \mathrm{h}$ and then decreased to follow the target speed. In the other sections, the tractor followed the desired speed well through the control of the engine torque and the HSU stroke (Figure $12 \mathrm{~b}, \mathrm{c}$ ). Figure $12 \mathrm{f}$ shows the engine OOL and engine actual operating points. The demanded engine speed was determined from the 00L(Figure 9), which provides the minimum fuel consumption. In region $\mathrm{B}$, since the required power(road load) is relatively small compared with that of working mode, the OOL engine speed was selected around $1000 \mathrm{rpm}$ (Figure 12d, $t=0 \sim 38 s$ ). After $t=38 s$, however, the HSU stroke was limited to the maximum $\left(i_{\text {stroke }}=1.0\right)$ (Figure $\left.12 \mathrm{~b}\right)$, and the OOL operation was no longer possible. As the tractor speed increased, the engine operated in a region out of the OOL (region C). This is because the planetary gear of the HMT was assumed to be a single-speed gear with the gear ratio of 1:2. Therefore, to move the engine operation from region $\mathrm{C}$ to the $\mathrm{OOL}$, the transmission range must be extended by adding the multi-step gear ratio of the planetary gear set for the given HSU stroke and the tractor speed range. 


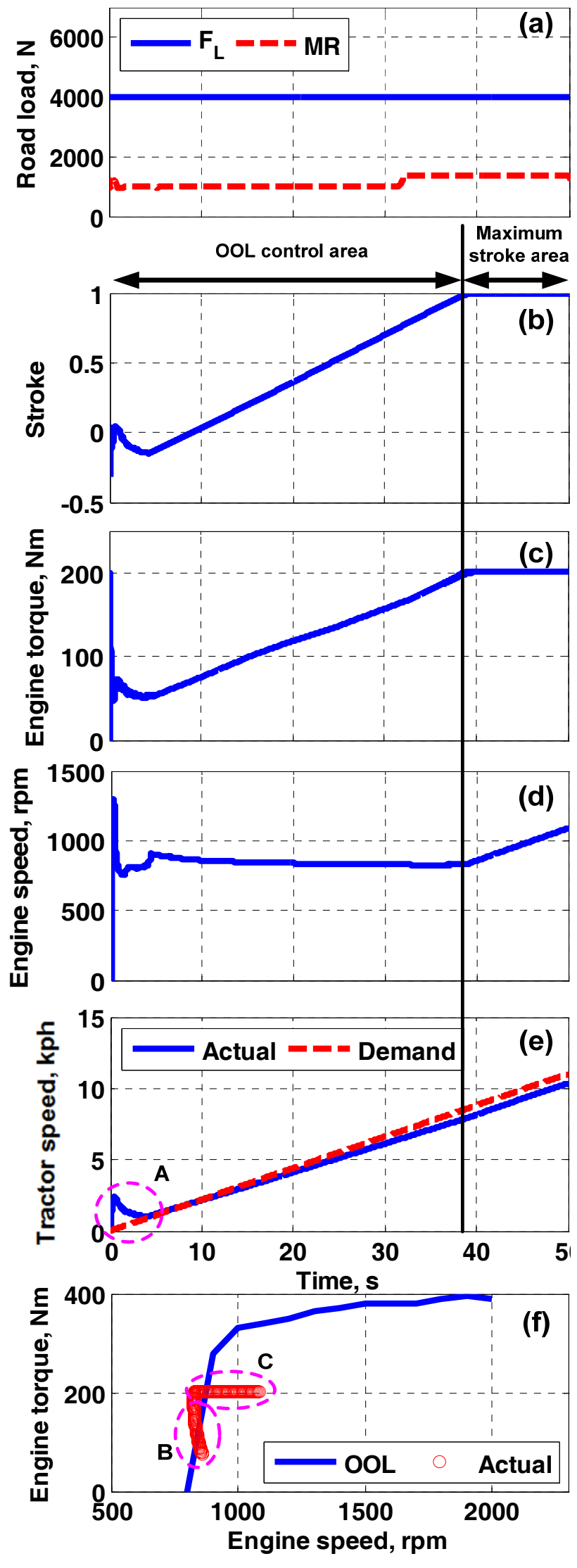

Figure 12. Simulation results for the driving mode.

\section{Conclusions}

A performance simulator of the HMT tractor was developed. The HMT was modeled considering the efficiency and response of the HSU. For the efficiency of the HSU, the test results of the efficiency with respect to the stroke, operating speed, and pressure were used, and dynamic models for the HSU swash plate control system and hydraulic control valves were derived. For the planetary gear of the HMT, the output speed and torque were modeled with the engine speed and torque, and the HSU stroke. Furthermore, the longitudinal dynamic equation of the tractor was derived considering the traction load, running resistance, and PTO output torque.

Based on the dynamic models of the HMT tractor, a performance simulator was developed. The HMT tractor simulator consists of the AMESim model of the HMT, engine and tractor dynamics and MATLAB/Simulink interface of the driver model, a controller, and a road load. Using the simulator, the performance of the HMT tractor was evaluated for the working mode and driving mode. It was found from the simulation results that the desired engine speed and tractor speed can be maintained by the engine torque and HSU stroke control for various load conditions.

\section{Conflict of Interest}

No potential conflict of interest relevant to this article was reported.

\section{Acknowledgement}

This research was supported by the Ministry for Food, Agriculture, Forestry and Fisheries and iPET (Korea Institute of Planning and Evaluation for Technology in Food, Agriculture, Forestry and Fisheries) through the Advanced Production Technology Development Program.

\section{References}

Aitzetmüller, H. 2000. Steyr S-matic - The future CVT system. FISITA, F2000A130.

Brixius, W. W. 1987. Traction prediction equations for 
bias-ply tires. ASAE Paper No. 871622. St. Joseph, Mich.:ASAE.

Casoli, P., A. Vacca, G. L. Berta, S. Meleti and M. Vescovini. 2007. A numerical model for the simulation of Diesel/CVT power split transmission. $8^{\text {th }}$ International Conference ${ }^{\text {on }}$ Engines ${ }^{\text {for }}$ Automobile, SAE 2007-24-0137.

Grisso, R. D and F. M. Zoz. 2003. Traction and tractor performance. ASAE Distinguished Lecture No. 27, pp. $1-48$.

Grisso, R. D., J. V. Perumpral and F. M. Zoz. 2007. Spreadsheet for matching tractors and drawn implements. Applied Engineering in Agriculture 23(3):259-265.

Kugi, A., K. Schlacher, H. Aitzetmüller and G. Hirmann. 2000. Modeling and simulation of a hydrostatic transmission with variable-displacement pump. Mathematics and Computers in Simulation 53(2000):409-414.

Lee, D. H., K. S. Lee and W. Y. Park. 2009. A study on traction prediction of agricultural tractor by empirical method. Journal of Biosystems Engineering 34(5):
297-304 (In Korean, with English abstract).

LMS Imagine. 2010. AMESim Application manuals. Rev 10. LMS Imagine SA.

Ortwig, H. 2002. New method of numerical calculation of losses and efficiencies in hydrostatic power transmissions. SAE International Off-Highway Congress co-located with CONEXPO-CON/AGG, SAE 2002-01-1418.

Park, K. M., Y. B. Ham, J. D. Jo and K. Y. Kim. 2002. The performance evaluation of servo regulator for swash plate tilting angle control of variable displacement type hydraulic piston pump. KSAE symposium, Nov, 2002, 854-859.

Ryu, K. H. 2004. Tractor engineering principles. Munundang. Xu, L., Z. Zhou, Q. Cao and M. Zhang. 2010. Study on matching strategies and simulation of hydro-mechanical continuously variable transmission system of tractor. IEEE International Conference on Intelligent Computation Technology and Automation, pp. 527-530. 